\title{
H3K9ac of TGF $\beta R$ in human umbilical cord: a potential biomarker for evaluating cartilage differentiation and susceptibility to osteoarthritis via a two-step strategy
}

Yongjian $\mathrm{Qi}^{1,2+}$, Bin $\mathrm{Li}^{1,2+}$, Yinxian Wen ${ }^{1,2+}, \mathrm{Xu} \mathrm{Yang}^{2}$, Biao Chen ${ }^{1,2}$, Zheng He $\mathrm{e}^{1,2}$, Zhe Zhao ${ }^{1}$, Jacques Magdalou ${ }^{3}$, Hui Wang ${ }^{2,4^{*}}$ and Liaobin Chen ${ }^{1,4^{*}}$

\begin{abstract}
Background: Epidemiological investigation and our previous reports indicated that osteoarthritis had a fetal origin and was closely associated with intrauterine growth retardation (IUGR). Human Wharton's jelly-derived mesenchymal stem cells (WJ-MSCS) could be programmable to "remember" early-life stimuli. Here, we aimed to explore an early-warning biomarker of fetal-originated adult osteoarthritis in the WJ-MSCs.

Methods: Firstly, two kinds of WJ-MSCs were applied to evaluate their chondrogenic potential in vitro through inducing chondrogenic differentiation as the first step of our strategy, one from newborns with IUGR and the other from normal newborns but treated with excessive cortisol during differentiation to simulate the excessive maternal glucocorticoid in the IUGR newborns. As for the second step of the strategy, the differentiated WJ-MSCs were treated with interleukin $1 \beta(\mathrm{IL}-1 \beta)$ to mimic the susceptibility to osteoarthritis. Then, the expression and histone acetylation levels of transforming growth factor $\beta$ (TGF $\beta$ ) signaling pathway and the expression of histone deacetylases (HDACs) were quantified, with or without cortisol receptor inhibitor RU486, or HDAC4 inhibitor LMK235. Secondly, the histone acetylation and expression levels of TGF $\beta R I$ were further detected in rat cartilage and human umbilical cord from IUGR individuals.

Results: Glycosaminoglycan content and the expression levels of chondrogenic genes were decreased in the WJMSCs from IUGR, and the expression levels of chondrogenic genes were further reduced after IL-1 $\beta$ treatment, while the expression levels of catabolic factors were increased. Then, serum cortisol level from IUGR individuals was found increased, and similar changes were observed in normal WJ-MSCs treated with excessive cortisol. Moreover, the decreased histone 3 lysine 9 acetylation (H3K9ac) level of TGF $\beta R$ I and its expression were observed in IUGRderived WJ-MSCs and normal WJ-MSCs treated with excessive cortisol, which could be abolished by RU486 and (Continued on next page)
\end{abstract}

\footnotetext{
*Correspondence: wanghui19@whu.edu.cn; lbchen@whu.edu.cn

${ }^{\dagger}$ Yongjian Qi, Bin Li and Yinxian Wen contributed equally to this work.

${ }^{2}$ Hubei Provincial Key Laboratory of Developmentally Originated Disease, Wuhan 430071, China

'Department of Orthopedic Surgery, Zhongnan Hospital of Wuhan University, Wuhan 430071, China

Full list of author information is available at the end of the article
}

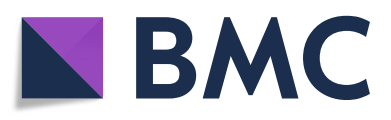

(- The Author(s). 2021 Open Access This article is licensed under a Creative Commons Attribution 4.0 International License, which permits use, sharing, adaptation, distribution and reproduction in any medium or format, as long as you give appropriate credit to the original author(s) and the source, provide a link to the Creative Commons licence, and indicate if changes were made. The images or other third party material in this article are included in the article's Creative Commons licence, unless indicated otherwise in a credit line to the material. If material is not included in the article's Creative Commons licence and your intended use is not permitted by statutory regulation or exceeds the permitted use, you will need to obtain permission directly from the copyright holder. To view a copy of this licence, visit http://creativecommons.org/licenses/by/4.0/ The Creative Commons Public Domain Dedication waiver (http://creativecommons.org/publicdomain/zero/1.0/) applies to the data made available in this article, unless otherwise stated in a credit line to the data. 


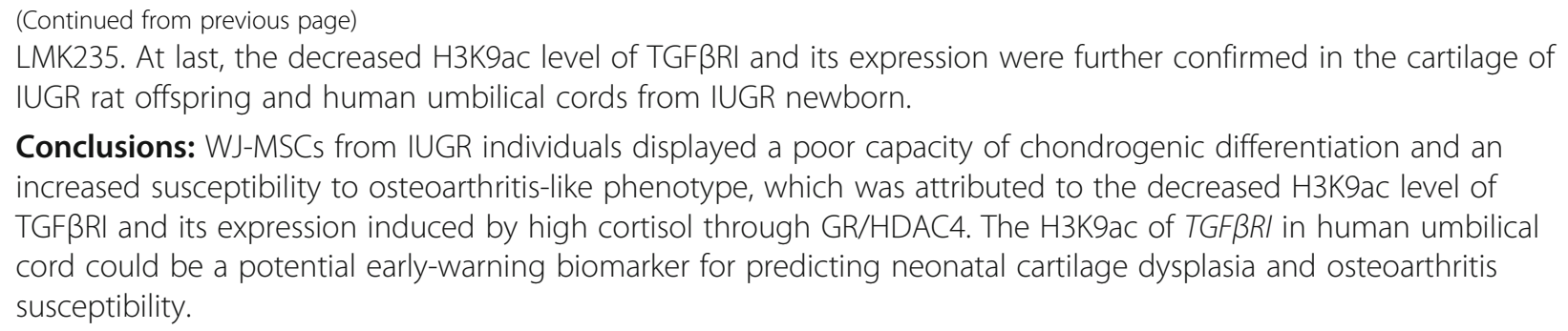

Keywords: Biomarker, Chondrogenic differentiation, Osteoarthritis, Transforming growth factor $\beta$ receptor I, Wharton's jelly-derived mesenchymal stem cells

\section{Background}

Osteoarthritis is a chronic joint disease characterized by articular cartilage degeneration, which has long been considered as an age-related degenerative disease. However, epidemiological investigations have shown that osteoarthritis of multiple joints, such as the hand and hip, is closely associated with low birthweight [1-5]. Intrauterine growth retardation (IUGR) refers to fetal growth restriction caused by various prenatal adverse factors, with the main manifestations being multiple organ developmental dysfunction, growth retardation, and low birthweight [6]. IUGR diagnosis criterion is that baby weight at $10 \%$ or two or more standard deviations less than the mean body weight of normal babies at the same gestational age $[7,8]$. Our previous studies found that prenatal exposure to xenobiotics (e.g., caffeine, nicotine, and ethanol) and food restriction could result in IUGR of rat offspring [9-14], and the IUGR rats exhibited persistent cartilage dysplasia and increased susceptibility to osteoarthritis in adulthood [14-22]. All these reports indicate that osteoarthritis has a fetal origin [23]. Considering the substantial healthcare resources and costs associated with osteoarthritis therapy [24], it is necessary to explore the early-warning marker of fetaloriginated osteoarthritis, which could change the current strategy for osteoarthritis prevention by targeting earlylife factors.

It is known that prenatal baseline levels of glucocorticoids (cortisol in humans and corticosterone in rodents) play an important role in the morphological and functional maturation of fetal tissues [25]. However, high levels of serum glucocorticoids could cause abnormal fetal development [25]. Several studies have demonstrated that increased level of glucocorticoids is positively correlated with the incidence of IUGR in fetuses $[26,27]$. "Intrauterine programming" refers to the longterm or permanent functional changes in an individual due to adverse prenatal conditions during fetal development [27]. Multiple reports suggested that excessive maternal glucocorticoid might be the trigger for intrauterine programming and that excessive glucocorticoids could induce long-term changes in the expression of multiple genes through genetic imprinting, which leads to persistent changes in fetal structure and function [28, 29]. Furthermore, it has been indicated that epigenetic alterations might act as more stable and reliable molecular markers of early-life events than the expression of the target genes [30]. Our previous studies have confirmed the "excessive maternal glucocorticoid" phenomenon in IUGR offspring with prenatal xenobiotic exposure, which might trigger the susceptibility to osteoarthritis of these IUGR offspring [13, 31, 32]. Accordingly, we speculated that fetal-originated osteoarthritis might be attributed to the alterations in epigenetic programming induced by maternal glucocorticoid overexposure. The abnormal epigenetic alterations could be early biomarkers for predicting the adult osteoarthritis with fetal origination.

Human Wharton's jelly-derived mesenchymal stem cells (WJ-MSCs) are multipotent and can be induced to differentiate into chondrocytes in vitro [33, 34]. Increasing evidence have indicated that stem cells, including WJ-MSCs, could be the targets of inappropriate environments and might be programmable to "remember" early-life stimuli that would affect their function in adult life [35-38]. Moreover, several reports have suggested that human WJ-MSCs from small for gestational age infants might preserve some identifiable molecular pathways and epigenetic markers [37, 39]. These results indicated that human WJ-MSCs might be appropriate for developing a cell model in vitro, to elucidate potential molecular mechanisms of the fetal origination of adult osteoarthritis and predict cartilage dysplasia and subsequent susceptibility to adult osteoarthritis.

In this study, we established a two-step model based on three-dimensional chondrogenic differentiation of WJMSCs to mimic cartilage development in utero and the inflammatory stimulation that had occurred under unfavorable conditions in adulthood in vivo. We aimed to investigate the capacity of chondrogenic differentiation of human WJ-MSCs from IUGR newborns and the subsequent susceptibility to an osteoarthritis-like phenotype. 
Furthermore, we sought to elucidate the initial factor and potential pathway programmed by epigenetic modification changes involved in these phenomena. Finally, the epigenetic imprinting was verified in the rat IUGR models and human umbilical cord with IUGR, which provided a promising early-warning biomarker for fetal-originated adult osteoarthritis.

\section{Methods}

\section{Clinical populations and sample collection}

With the written consent of the parents and the approval (No. 2016016) of the Ethics Committee of our institute, all umbilical cord specimens were obtained immediately from the newborn by cesarean operation at the Zhongnan Hospital of Wuhan University and collected in sterile boxes containing normal saline.

\section{Enzyme-linked immunosorbent assay (ELISA)}

The concentrations of serum cortisol were measured by ELISA kit (R\&D, Minneapolis, MN, USA), following the manufacturer's protocols.

\section{Isolation and culture of human WJ-MSCs}

Human WJ-MSCs were isolated as previously described [40]. Briefly, MSCs were isolated from collected human umbilical cords within $2 \mathrm{~h}$. Removing the umbilical arteries and umbilical vein, Wharton's jelly was peeled off from the remaining part of the umbilical cords and transferred to a sterile container and then cut into pieces smaller than $0.5 \mathrm{~cm}^{3}$. The minced Wharton's jelly was digested for $4 \mathrm{~h}$ in a $50-\mathrm{ml}$ sterile centrifuge tube with 30-ml culture medium containing collagenase of type I (Invitrogen, Thermo Fisher Scientific Inc., USA) at $0.2 \%$ in an incubator ( $5 \%$ carbon dioxide, $\left.37^{\circ} \mathrm{C}\right)$. After centrifuging the liquid at $300 \times g$ for $15 \mathrm{~min}$ and discarding the supernatants, the cells were resuspended in DMEM/F12 medium (Gibco BRL, Thermo Fisher Scientific Inc., USA) with $10 \%$ fetal bovine serum (Gibco BRL, Thermo Fisher Scientific Inc., USA) and 1\% penicillinstreptomycin (Gibco BRL, Thermo Fisher Scientific Inc., USA) in humidified air with $5 \%$ carbon dioxide at $37^{\circ} \mathrm{C}$. The WJ-MSCs were passaged once the flask reached approximately $80 \%$ confluence and the fourth passage was used for the next experiments.

\section{Characterization of WJ-MSCs by flow cytometry}

Flow cytometry was utilized to determine the stemness features of WJ-MSCs by analysis of specific cell surface markers. After being trypsinized, the cells were resuspended in $0.5 \mathrm{ml}$ phosphate-buffered saline (PBS) and incubated for $1 \mathrm{~h}$ at room temperature with conjugated primary antibodies (FITC-CD34, CD45, CD73, CD90 and CD105, eBioscience, San Diego, CA, USA) and resuspended in $0.5 \mathrm{ml}$ PBS and then analyzed using a BD FACS Canto flow cytometer (Becton Dickinson).

\section{Establishment of two-step cell model and cell treatment} WJ-MSCs were cultured in alginate beads following the modified method described by De Ceuninck et al. [41]. Briefly, WJ-MSCs cultured in monolayer were trypsinized, washed, and centrifuged. Then, the WJ-MSCs were suspended at a concentration of $3 \times 10^{6}$ cells $/ \mathrm{ml}$ in a $1.25 \%$ alginate (Sigma-Aldrich, St. Louis, MO, USA) in $0.15 \mathrm{M}$ $\mathrm{NaCl}$ and slowly dropped into $102 \mathrm{mM} \mathrm{CaCl}_{2}$ solution to form alginate beads. The beads were cultured with a chondrogenic medium: DMEM/F12 medium containing 1\% insulin-transferrin-selenous (ITS) (Sigma, St. Louis, MO, USA), $100 \mathrm{nM}$ dexamethasone (Sigma, St. Louis, MO, USA), and $10 \mathrm{ng} / \mathrm{ml}$ transforming growth factor $\beta 1$ (TGFB1) (Sigma, St. Louis, MO, USA). After chondrogenic differentiation of 3 weeks, some beads were collected for detection. The remaining beads in the plates were treated with DMEM/F12 medium containing $10 \mathrm{ng} / \mathrm{ml}$ recombinant human interleukin-1 $\beta$ (rhIL-1 $\beta$, Prop Tech, London, UK) for 24-h and then collected for analysis.

In the experiment of differentiation and IL-1 $\beta$ induction, all the specimens were divided into three groups, namely the control, IUGR, and cortisol-treated groups, among which, the control group refers to WJ-MSCs from normal newborns without cortisol treatment, the IUGR group refers to WJ-MSCs from IUGR newborns without cortisol treatment, and the cortisol-treated groups refer to WJ-MSCs from normal newborns treated by different concentration of cortisol, including 300 and 1200 nM. RU486 (10 $\mu$ M) (Sigma-Aldrich, St. Louis, MO, USA) and LMK235 (100 nM) (Sigma-aldrich, St. Louis, MO, USA) were respectively utilized with different concentrations of cortisol (300 and $1200 \mathrm{nM}$ ) to treat the WJ-MSCs during chondrogenic differentiation in a 6-well culture plate.

\section{Cell viability analysis}

After 21-day differentiation of WJ-MSCs, 8 alginate beads were randomized taken to 96 -well plate and were given $50 \mu \mathrm{L}$ basic culture media and $20 \mu \mathrm{L}$ MTS solution (Promega, USA) to incubate for $2 \mathrm{~h}$; after that, the alginate beads were dissolved by beads solution (containing $12 \mathrm{mg} / \mathrm{mL} \mathrm{NaCl}, 16.20 \mathrm{mg} / \mathrm{mL}$ trisodium citrate dehydrate, $2.4 \mathrm{mg} / \mathrm{mL}$ HEPES) for $1 \mathrm{~min}$, and finally mix the cell suspension well. Then, 490-nm wavelength was selected to determine the absorption value of various apertures at the GENios VA200 enzyme standard (TECAN, Austria), and the results were recorded.

\section{Alcian blue and safranin-O staining of alginate beads}

After differentiation of human WJ-MSCs and IL-1 $\beta$ induction, 3 beads in each group were harvested and fixed 
in $10 \%$ buffered paraformaldehyde at room temperature. Then, these beads were rinsed with phosphate-buffered saline (PBS), serially dehydrated, infiltrated with arnyl acetate, paraffin embedded, and sectioned at 5- $\mu \mathrm{m}$ thickness for staining [42]. In detail, the sections were rinsed with PBS and then stained overnight with $1 \%$ Alcian blue dye at $\mathrm{pH} 1.0$ or $0.1 \%$ aqueous safranin-O for 10 $\mathrm{min}$ at room temperature. Images were captured with an Olympus AH-2 light microscope (Olympus, Tokyo, Japan) and quantitatively analyzed with ImageJ software (National Institutes of Health, Bethesda, MD) using methodology as previously described [43, 44]. Images were made binary under an RGB threshold, and "Particle Analysis" was utilized to measure the positive area and normalized to the control group.

\section{Total RNA extract and RT-qPCR}

Total RNA was isolated from the collected alginate beads and rat knee cartilage, using Trizol reagent (Invitrogen, Thermo Fisher Scientific Inc., USA) following the manufacturer's protocol. The concentration and purity of the isolated RNA were determined by spectrophotometer and adjusted to $1 \mu \mathrm{g} / \mu \mathrm{L}$. Total RNA was stored in diethyl pyrocarbonate- $\mathrm{H}_{2} \mathrm{O}\left(\mathrm{DEPC}-\mathrm{H}_{2} \mathrm{O}\right)$ at $-80^{\circ} \mathrm{C}$. For RT-qPCR analysis, single-strand cDNA was prepared from $2 \mu \mathrm{g}$ of total RNA according to the protocol of the Exscript RT reagent kit. Primers were designed using Primer Premier 5.0 and their sequences are shown in Table 1. PCR assays were performed in 384-well optical reaction plates using the RG-3000 Rotor-Gene 4 Channel Multiplexing System (Corbett Research Pty Ltd., Sydney, Australia) in a total volume of $25 \mu \mathrm{L}$ reaction mixture containing $2 \mu \mathrm{L}$ of $0.1 \mu \mathrm{g} / \mu \mathrm{L}$ cDNA template, $0.5 \mu \mathrm{L}$ of $10 \mu \mathrm{mol} / \mathrm{L}$ each primer, $12.5 \mu \mathrm{L}$ of $2 \times$ Premix Ex Taq, $0.5 \mu \mathrm{L}$ of $20 \times$ SYBR Green I, and $9 \mu \mathrm{L}$ of DEPC$\mathrm{H}_{2} \mathrm{O}$. To precisely quantify the transcript expression of these genes including $\alpha 1$ chain of type II collagen $(C O L 2 A 1)$, aggrecan $(A C A N)$, transforming growth factor $\beta$ receptor I $(T G F \beta R I)$, matrix metalloproteinase 3 (MMP3), MMP13, a disintegrin and metalloprotease with thromospondinmotifs 5 (ADAMTS5) and histone deacetylation $(H D A C)$, the mRNA level of glyceraldehyde phosphate dehydrogenase $(G A P D H)$ was measured as the quantitative control, and each sample was normalized on the basis of GAPDH mRNA content. PCR cycling conditions were as follows: $95^{\circ} \mathrm{C}, 15 \mathrm{~s}$ for predenaturation, and $95^{\circ} \mathrm{C}, 5 \mathrm{~s}$ for denaturation; annealing conditions for each gene are listed in Table 1.

\section{Chromatin immunoprecipitation (ChIP) assay}

Cells in Alginate beads were cross-linked with 1\% formaldehyde before sonicating in SDS lysis buffer. DNA in cell lysates was sheared to length of approximately 200 base pairs. Fragmented chromatin was first pre-cleared with protein A-sepharose $4 \mathrm{~B}$ and rabbit IgG for $2 \mathrm{~h}$. Before immunoprecipitating with fresh protein Asepharose $4 \mathrm{~B}$ and antibody include anti-histone 3 lysine 9 acetylation (H3K9ac) and anti-H3K27ac (Abcam, USA) at $4{ }^{\circ} \mathrm{C}$ overnight. Sepharose beads were washed before eluting with $1 \%$ SDS followed by reverse crosslinking at $65^{\circ} \mathrm{C}$ overnight. The samples were then placed in a $65^{\circ} \mathrm{C}$ water bath overnight to reverse formaldehyde cross-linking and subsequently were purified using PCR purification kits. The isolated DNA was then assayed using RT-qPCR; the primer sequences of the promoters of indicated genes are shown in Table 2. The input values were compared to the immunoprecipitated samples, with the IgG negative controls values subtracted as background. The calculated errors in all of the graphs depicting ChIP data represent the standard deviations for three replicate RT-qPCRs for precipitated chromatin,

Table 1 Oligonucleotide primers used for RT-qPCR conditions

\begin{tabular}{|c|c|c|c|}
\hline Genes & Forward primer & Reverse primer & Annealing \\
\hline Homo GAPDH & GAAATCCCATCACCATCTTCCAG & GAGTCCTTCCACGATACCAAAG & 60 \\
\hline Homo COL2A1 & GCTCCCAGAACATCACCTACCA & ACAGTCTTGCCCCACTTACCG & 60 \\
\hline Homo ACAN & AAGGGCGAGTGGAATGATGT & CGCTTCTGTAGTCTGCGTTTGT & 60 \\
\hline Homo TGF $\beta R I$ & GCAATGGGCTTAGTATTCTGGG & TCCTGTTGACTGAGTTGCGATAAT & 60 \\
\hline Homo Smad2 & TCTGGGCAGCCGTAAGTTAA & CCACTGTTGCGACGATTAGG & 60 \\
\hline Homo Smad3 & CGGTTCACAAGGCTCAAGAG & AAGTGGGTCCTCAGAAGTGG & 60 \\
\hline Homo MMP3 & AATCAATTCTGGGCTATCAGAGG & GCATCAATCTITGAGTCAATCCC & 60 \\
\hline Homo MMP13 & CAGAACTTCCCAACCGTATTGAT & TGTATTCAAACTGTATGGGTCCG & 60 \\
\hline Homo ADAMTS5 & TTCTCCAAAGGTGACCGATG & СCTCCACATACTCCGCACTTG & 60 \\
\hline Rat GAPDH & GCAAGTTCAACGGCACAG & GCCAGTAGACTCCACGACA & 60 \\
\hline Rat TGFBRI & CTCGAGCAGTTACAAAGGGC & CTCGAGCAGTTACAAAGGGC & 60 \\
\hline
\end{tabular}

GAPDH, glyceraldehyde phosphate dehydrogenase; COL2A1, a1 chain of type II collagen; $A C A N$, Aggrecan; TGF $\beta R I$, transforming growth factor $\beta$ receptor I; MMP3, matrix metalloproteinase 3; MMP13, matrix metalloproteinase 13; ADAMTS5, a disintegrin and metalloprotease with thromospondinmotifs 5 
Table 2 Oligonucleotide primers and PCR conditions for CHIP-PCR

\begin{tabular}{llll}
\hline Genes & Forward primer & Reverse primer & Annealing \\
\hline Homo COL2A1 & TGCAGGGAAGGCTAAAAGA & GGAGCCCACAGAGATTCAGA & 60 \\
Homo ACAN & CTCGAACTCAGTCCCACCTT & ACCTGCCCCTAACCAAAGAT & 60 \\
Homo TGF $\beta R I$ & ATCGGGAAGGGGTTTAGAG & AGATCCTGAGCCCAAACACA & 60 \\
Homo Smad2 & CGAGTGCCTAAGTGATAGT & AGACTGAGCCAGAAGAGC & 60 \\
Homo Smad3 & GGGCTTTGAGGCTGTCTA & CCAACCCGATCCCTTAC & 60 \\
Rat TGF $\beta R l$ & ACTGGAATTGAGGAGGGCA & TAGACCCGCTCCTCAATTCC & 60 \\
\hline
\end{tabular}

input chromatin, and background (i.e., chromatin precipitated with nonspecific IgG).

\section{Western blotting}

To obtain protein, the cells were harvested and dissolved in RIPA buffer. Protein concentrations were determined by BCA protein assay kit. Equal amounts of protein lysates $(30 \mu \mathrm{g} /$ lane) were loaded and resolved on $10 \%$ SDS polyacrylamide gel and then transferred onto nitrocellulose filter, and probed with rabbit anti-TGF $\beta R I$ (1:1000, Abcam, Inc., UK), COL2A1 (1:500, Abcam, Inc., UK), ACAN (1:1000, Abcam, Inc., UK), and GAPDH (1:1000, Abcam, Inc., UK) at $4{ }^{\circ} \mathrm{C}$ overnight. After incubation with horse radish peroxidase-conjugated secondary antibody, blots were developed by enhanced chemiluminescence following the manufacturer's protocol and visualized by exposure to a Fusion FX system (Vilber Lourmat, Marne-la-Vallée, France). Protein amount in electrophoresis gel was analyzed with Quantity One 4.6 analysis software (Bio-Rad Laboratories Inc., CA, USA).

\section{Establishment of animal models}

The animal experiment was performed in the Center for Animal Experiment of Wuhan University (Wuhan, China), which has been accredited by the Association for Assessment and Accreditation of Laboratory Animal Care International (AAALAC International). The protocol was approved by the Committee on the Ethics of Animal Experiments of the Wuhan University School of Medicine (Permit Number: 14016). All animal experimental procedures were performed in accordance with the Guidelines for the Care and Use of Laboratory Animals (eighth edition) by the National Research Council of the United States National Academies.

\section{In utero}

Specific pathogen-free (SPF) Wistar rats, females weighing 200-240 g and males weighing 260-300 g, were obtained from the Experimental Center of Hubei Medical Scientific Academy (No. 2009-0004, Hubei, China). Animals were housed (room temperature $18-22^{\circ} \mathrm{C}$; humidity $40-60 \%$ ), acclimated, and mated. Upon confirmation of mating by the appearance of sperm in a vaginal smear, the day was taken as gestational day (GD) 0 .
Pregnant females were then transferred to individual cages. Pregnant rats were randomly divided into two groups: the control group, and prenatal xenobiotics exposure (PXE) group. Starting from GD9 until GD20, the PXE group were administrated of caffeine $(120 \mathrm{mg} / \mathrm{kg} /$ d), nicotine $(2 \mathrm{mg} / \mathrm{kg} / \mathrm{d})$, ethanol $(4 \mathrm{~g} / \mathrm{kg} / \mathrm{d})$, or dexamethasone $(0.2 \mathrm{mg} / \mathrm{kg} / \mathrm{d})$ as previously described [19$22]$, while the control group was given the same volume of distilled water. On GD20, 8 randomly selected pregnant rats with 10-14 live fetuses from each group were anesthetized. The male fetuses were quickly removed, weighed, and IUGR was diagnosed when the body weight of a fetus was two standard deviations less than the mean body weight of fetuses in the control group. Fetal knee joints were separated under a dissecting microscope and collected from each littermate were pooled together and immediately frozen in liquid nitrogen, followed by storage at $-80^{\circ} \mathrm{C}$ for analyses. A portion of fetal knee joints (one per litter) were fixed in $4 \%$ paraformaldehyde for morphological observation.

\section{After birth}

On the postnatal week (PW) 1, we weighed the litter sizes and recorded the weight gain. The pups in each litter were randomly divided into 4 batches, according to the postnatal week respectively named as PW6. For each batch, 10 male pups for control or PXE group were selected randomly, and all of the pups were weaned to an ad libitum diet before being sacrificed. On PW6, the corresponding batches of rats were anesthetized with ether and decapitated to collect knee tissues. For histological analysis, the knee joints were fixed in $4 \%$ paraformaldehyde for 3 days, decalcified in 20\% EDTA (pH 7.4) for 21 days, and embedded in paraffin. Serial 5 - $\mu$ m-thick sagittal sections were cut across the whole joint. The remaining knee samples were used for RT-qPCR and ChIP-PCR.

\section{Immunofluorescence staining of cartilage samples}

Sections were deparaffinized in xylene and hydrated through a graded series of alcohols. Hydrated sections were then applied for immunofluorescence. Briefly, after antigen retrieval with boiling in sodium citrate buffer, sections were then blocked in serum for $30 \mathrm{~min}$ followed 
by incubation with the primary antibody rabbit antiTGFßRI (Abcam, Inc., UK) in a humidified chamber at $4{ }^{\circ} \mathrm{C}$ overnight. Following washing with PBS, the sections were incubated with Alexa Fluor 594-labeled secondary antibody (red color) (1:100) (Proteintech) in darkness at room temperature for $2 \mathrm{~h}$. Nuclei were counterstained with DAPI (blue color) in darkness for $5 \mathrm{~min}$. The staining was examined using an Olympus AH-2 light microscope (Olympus, Tokyo, Japan).

\section{Statistical analysis}

SPSS 17 (SPSS Science Inc., Chicago, IL) was used for data analysis. Quantitative data were expressed as the mean \pm S.E.M. and were evaluated with an independent samples $t$ test or using one-way ANOVA followed by Dunnett's post hoc Student's $t$ tests. Statistical significance was defined as $P<0.05$.

\section{Results}

Poor chondrogenic differentiation of WJ-MSCs from IUGR humans and subsequent susceptibility to the osteoarthritis-like phenotype upon IL-1 $\beta$ stimulation

To mimic the processes of cartilage development in utero and the inflammation during osteoarthritis process in vivo, we constructed a two-step cell culture model based on the human WJ-MSCs from IUGR individuals. Firstly, WJ-MSCs were obtained from the umbilical cord of the newborns diagnosed as IUGR [45]. Then, step one: WJ-MSCs from normal and IUGR individuals were induced to differentiate into chondrocytes in an alginate scaffold for 21 days, a standard process of chondrogenic differentiation in vitro [33]. Step two: the chondrogenic

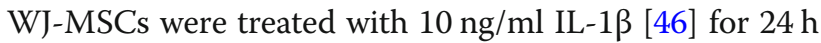
to evaluate their susceptibility to an osteoarthritis-like phenotype (Fig. 1a). Flow cytometry was performed to identify the 3rd generation of human WJ-MSCs (Fig. S1) as previously reported [47]. After chondrogenic differentiation, compared with those in the control group, the cell viability of the IUGR group had no significant change (Fig. S2A), Safranin-O and Alcian blue staining showed that glycosaminoglycan contents in the alginate were decreased $(P<0.01$, Fig. $1 \mathrm{~b}-\mathrm{d})$, and the mRNA expression levels of the phenotypic genes COL2A1 and $A C A N$ were significantly decreased $(P<0.01$, Fig. $1 \mathrm{e})$, but the mRNA expression levels of catabolic factors, including MMP3, MMP13, and ADAMTS5 were not changed (Fig. 1e). After IL-1 $\beta$ treatment, the glycosaminoglycan content and the expression of the phenotypic genes in the IUGR group were decreased more severely $(P<0.01$, Fig. $1 \mathrm{~b}-\mathrm{d}, \mathrm{f})$, while the mRNA expression levels of MMP3, MMP13, and ADAMTS5 were dramatically increased $(P<0.01$, Fig. 1e). All the above results suggested that WJ-MSCs from IUGR newborns had a poor capacity for chondrogenic differentiation and the subsequent differentiated chondrocytes were more susceptible to an osteoarthritis-like phenotype.

\section{Poor chondrogenic differentiation of normal WJ-MSCs induced by excessive cortisol and subsequent susceptibility to an osteoarthritis-like phenotype upon IL- $1 \beta$ stimulation}

To investigate whether maternal cortisol overexposure is the initial factor involved in these outcomes, we first detected concentrations of cortisol in the neonatal umbilical cord blood. The result showed that the cortisol level in samples from the IUGR group was significantly higher than the newborns with normal birthweight $(P<0.01$, Fig. S3), which was consistent with the result reported by Mericq et al. [48]. Taking the reported data and our present results into account, we chose $300 \mathrm{nM}$ cortisol as the physiological concentration and $600 \mathrm{nM}$ and 1200 $\mathrm{nM}$ as a series of pathological concentrations in vitro. Then, the chondrogenic potential of WJ-MSCs treated with different concentrations of cortisol and the subsequent susceptibility to an osteoarthritis-like phenotype were evaluated. Compared with the $300 \mathrm{nM}$ cortisol group, the cell viability in the 600 and $1200 \mathrm{nM}$ cortisol groups had no significant changes on 0 day and 21th day after chondrogenic differentiation (Fig. S2B), while the glycosaminoglycan staining in the $1200 \mathrm{nM}$ cortisol group was significantly decreased $(P<0.01$, Fig. $2 \mathrm{a}-\mathrm{c})$. The mRNA expression levels of COL2A1 and ACAN in the 600 and $1200 \mathrm{nM}$ groups were substantially reduced $(P<0.01$, Fig. $2 \mathrm{~d})$, while the mRNA expression levels of $M M P 3, M M P 13$, and ADAMTS5 were not changed (Fig. $2 d)$. After IL-1 $\beta$ treatment, the glycosaminoglycan staining $(P<0.01$, Fig. $2 \mathrm{a}-\mathrm{c})$ and mRNA levels of COL2A1 and $A C A N$ in the $1200 \mathrm{nM}$ cortisol group were decreased more markedly $(P<0.01$, Fig. 2 e). Simultaneously, the mRNA levels of $M M P 3, M M P 13$, and $A D A M$ TS5 were significantly enhanced $(P<0.01$, Fig. 2 e). All the above results suggested that normal WJ-MSCs treated with excessive cortisol presented an insufficient chondrogenic differentiation capacity and the subsequent differentiated chondrocytes were more susceptible to an osteoarthritis-like phenotype.

\section{Decreased H3K9ac level of TGF $\beta R I$ participated in the poor chondrogenic differentiation of human WJ-MSCs induced by excessive cortisol}

To explore the potential pathway involved in the poor chondrogenic differentiation of WJ-MSCs from IUGR, we focused on the TGF $\beta$ signaling pathway, which has been reported to be indispensable for the chondrogenic differentiation of mesenchymal stem cells (MSCs) both in vivo and in vitro $[40,49,50]$. The results showed that the mRNA expression of TGFBRI was lower in the chondrogenic WJ-MSCs from IUGR individuals than that in 


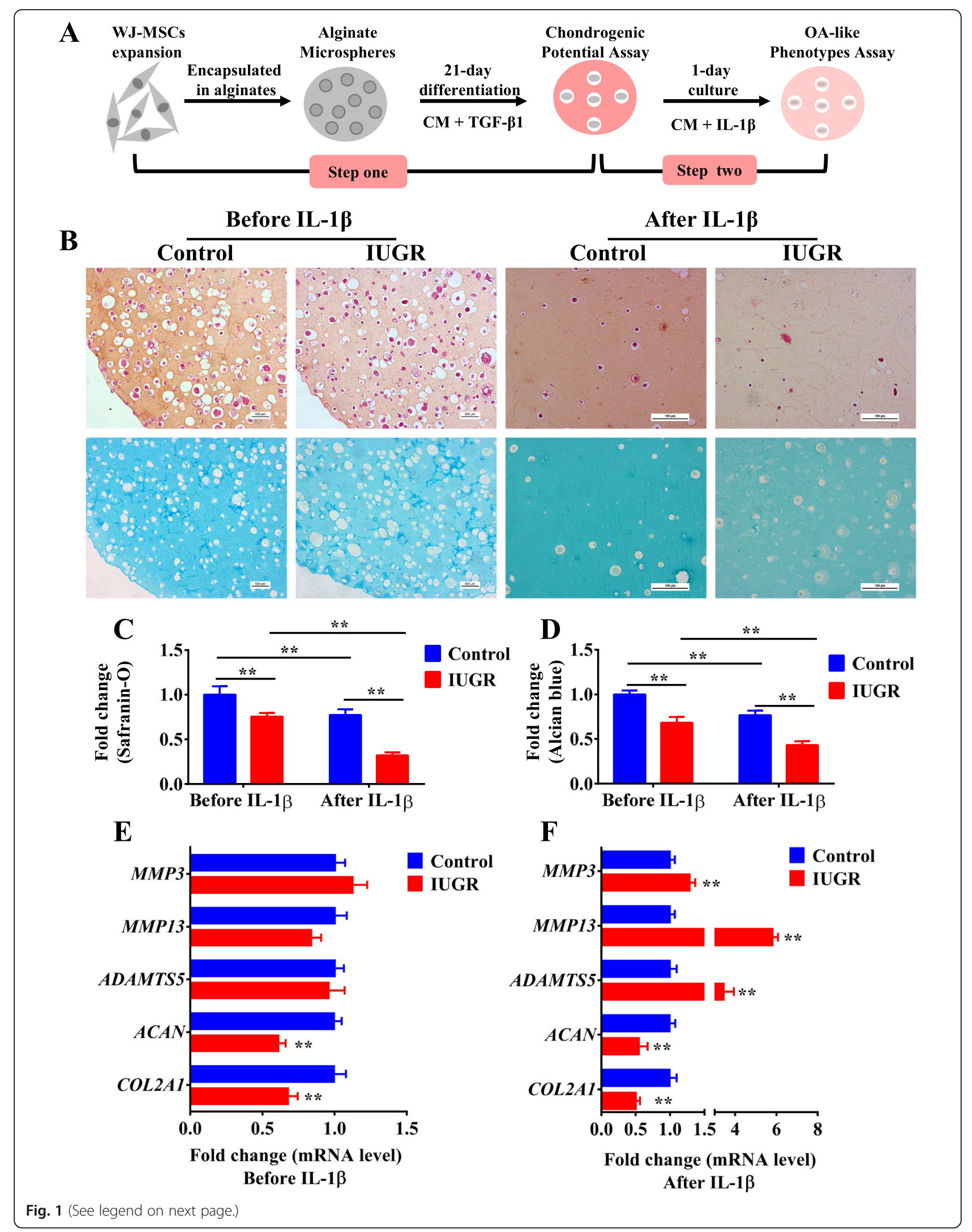


(See figure on previous page.)

Fig. 1 Poor chondrogenic differentiation of WJ-MSCs from IUGR humans and subsequent increased susceptibility to an osteoarthritis-like phenotype induced by IL-1 $\beta$. a A schematic of a two-step cell culture model for evaluating chondrogenic differentiation and susceptibility to an osteoarthritis-like phenotype. b Safranin-O and Alcian blue staining for glycosaminoglycan in WJ-MSCs after chondrogenic differentiation for 21 days and IL-1 $\beta$ treatment for 1 day in the control and IUGR groups. c, d Relative quantification of Safranin-O and Alcian blue staining, $n=5$. e, $\mathbf{f}$ RT-qPCR analysis of COL2A1, ACAN, MMP3, MMP13, and ADAMTS5 expression in WJ-MSCs after chondrogenic differentiation and IL-1 $\beta$ treatment in the control and IUGR groups, $n=5$. WJ-MSCs, Wharton's jelly-derived mesenchymal stem cells; IUGR, intrauterine growth retardation; IL-1 $\beta$, interleukin-1 $\beta$; CM, chondrogenic medium; TGF $\beta 1$, transforming growth factor $\beta 1$; RT-qPCR, real-time quantitative polymerase chain reaction; COL2A1, a1 chain of type II collagen; ACAN, aggrecan; MMP, matrix metalloproteinase; ADAMTS5, a disintegrin and metalloproteinase with thrombospondin motifs-5. Data are the mean \pm S.E.M. ${ }^{* *} P<0.01$ vs control

the individuals with normal birthweight $(P<0.01$, Fig. 3a), while the mRNA expression levels of Smad2 and Smad3 were unaffected. Moreover, similar results were observed in the groups treated with excessive cortisol $(P<0.01$, Fig. 3b). Such findings indicated that the poor chondrogenic differentiation of WJ-MSCs might be attributed to the decreased expression of TGFBRI.

Growing evidence indicates that excessive glucocorticoid has powerful effects on the epigenome to influence gene expression [28, 29]. Prenatal glucocorticoid exposure in a fetal guinea pig model resulted in an acute and substantial effect on the histone acetylation of target genes in the hippocampus [51]. Accordingly, we hypothesized that excessive cortisol might inhibit the expression of TGF $\beta R I$ through histone acetylation modification. To verify this hypothesis, ChIP-PCR was performed to examine the histone acetylation level of the TGFBRI in the differentiated cells. Interestingly, compared to the control group, the H3K9ac level of TGF $\beta R I$ in the IUGR group $(P<0.01$, Fig. $3 c)$ and excessive cortisol-treated groups $(P<0.01$, Fig. $3 \mathrm{~d})$ was decreased dramatically. However, the H3K27ac levels of $T G F \beta R I$ were not changed (Fig. 3e, f). Additionally, the H3K9ac and H3K27ac levels of Smad2, Smad3, COL2A1, and $A C A N$ did not differ among the groups (Fig. 3c-f). These results suggested that the reduced H3K9ac level of TGFBRI in human WJ-MSCs was induced by excessive cortisol, which resulted in the decreased expression of $T G F \beta R I$ and further contributed to the poor chondrogenic differentiation in vitro.

\section{GR/HDAC4 participated in the reduced H3K9ac level of $T G F \beta R I$ induced by excessive cortisol}

It has been reported that glucocorticoid regulates the expression of many target genes through the glucocorticoid receptor (GR) and epigenetic enzymes, such as HDACs $[52,53]$. Thus, to elucidate the potential mechanism of H3K9ac of TGF $\beta R I$ induced by excessive cortisol, we detected the expression of HDACs in WJ-MSCs. The results showed that the mRNA expression of $H D A C 4$ was significantly increased in a concentrationdependent manner in the cortisol groups of $600 \mathrm{nM}$ and $1200 \mathrm{nM}$ compared with that in the $300 \mathrm{nM}$ cortisol group $(P<0.01$, Fig. 4a). Then, RU486 (a GR antagonist) and LMK235 (a specific HDAC4 inhibitor) were utilized to verify the roles of GR and HDAC4. The results showed that, compared with the $300 \mathrm{nM}$ cortisol group, RU486 attenuated the increase of expression of HDAC4 induced by $1200 \mathrm{nM}$ cortisol $(P<0.01$, Fig. $4 \mathrm{~b})$. Furthermore, RU486 and LMK235 not only abolished the decrease in the H3K9ac level of TGFBRI induced by cortisol of $1200 \mathrm{nM}(P<0.05, P<0.01$, Fig. $4 \mathrm{c})$, but also reversed the reduced mRNA and protein levels of TGFBRI, COL2A1, and ACAN ( $P<0.01$, Fig. $4 \mathrm{~d}$, e). The results above suggested that GR, combined with HDAC4, participated in the decreased H3K9ac level of $T G F \beta R I$ induced by excessive cortisol, which led to the closed chromatin in the TGFBRI promoter region and further resulted in the decline in the transcriptional expression of TGFBRI.

\section{Decreased H3K9ac and expression levels of TGF $\beta R I$ were verified in IUGR individuals}

Our laboratory previously confirmed that IUGR rats induced by caffeine, nicotine, ethanol, and dexamethasone during pregnancy developed persistent chondrodysplasia and susceptibility to osteoarthritis in adulthood [19-22]; thus, we detected the H3K9ac level of TGFßRI and its expression in the cartilage of IUGR rat offspring. The results showed that the H3K9ac level of TGF $\beta R I$ and its mRNA and protein expression were decreased dramatically both in utero and at postnatal week 6 in the offspring rats with prenatal caffeine, nicotine, ethanol, and dexamethasone exposure $(P<0.01$, Fig. $5 \mathrm{a}-\mathrm{c})$. Furthermore, we collected the WJ-MSCs from the umbilical cord of human newborns and found that H3K9ac level of TGFßRI and its mRNA were all lower in the human newborns with low birthweight, when compared with those with normal birthweight $(P<0.01$, Fig. 6a, b).

\section{Discussion}

Poor chondrogenic differentiation of WJ-MSCs from IUGR humans and the subsequent increased susceptibility to the osteoarthritis-like phenotype were confirmed via a two-step cell culture model

During the process of chondrogenesis of MSCs, TGF $\beta 1$ in the medium induces the activation of a 


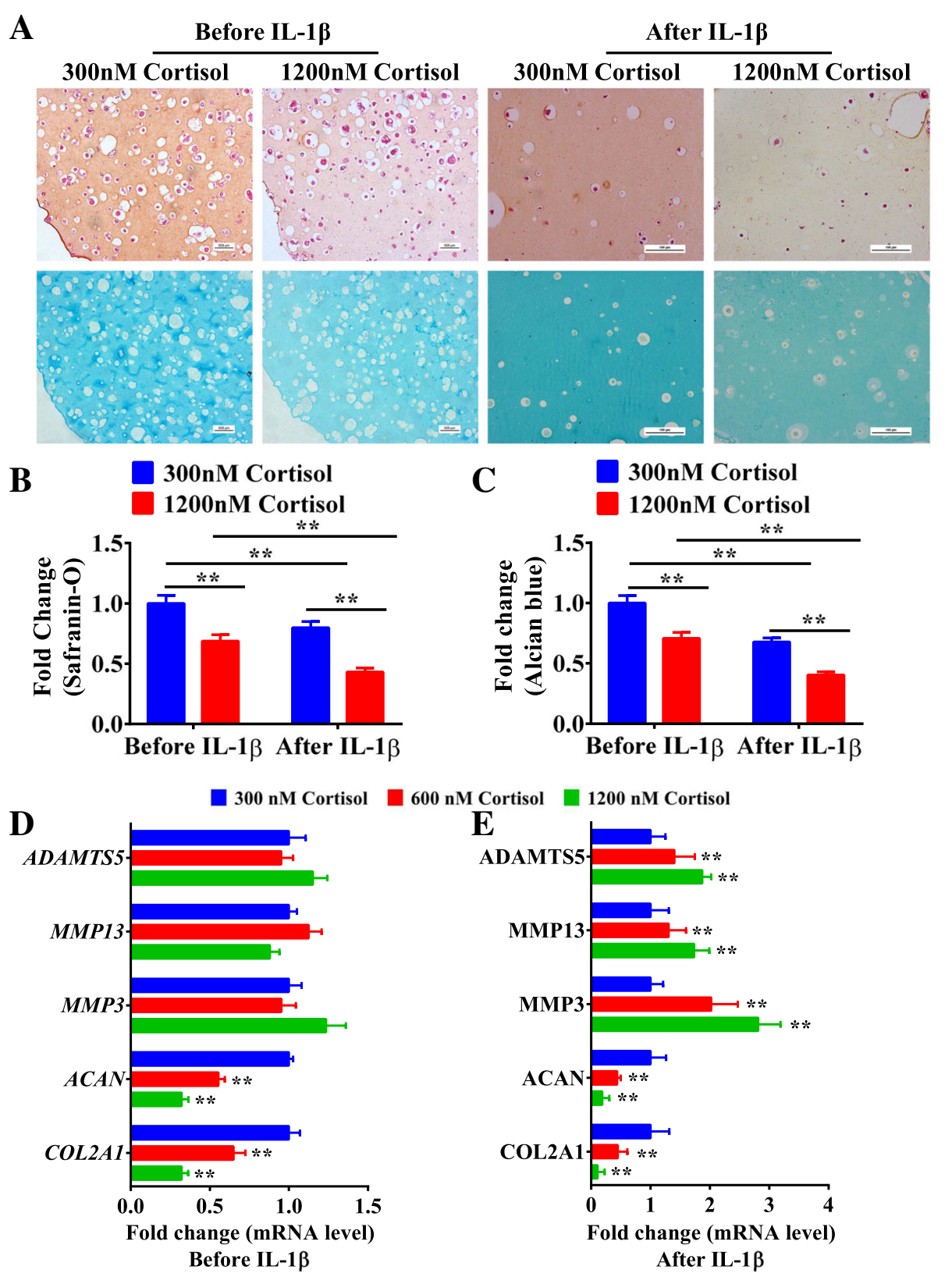

Fig. 2 Normal WJ-MSCs treated with high levels of cortisol presented a poor capacity for chondrogenic differentiation and subsequent increased susceptibility to an osteoarthritis-like phenotype induced by IL-1ß. a Safranin-O and Alcian blue staining for glycosaminoglycan in WJ-MSCs after chondrogenic differentiation for 21 days and IL-1 $\beta$ treatment for 1 day in 300,600, and $1200 \mathrm{nM}$ cortisol groups. b, c Relative quantification of Safranin-O and Alcian blue staining, $n=5$. d, e RT-qPCR analysis of COL2A1, ACAN, MMP3, MMP13, and ADAMTS5 expression after chondrogenic differentiation and IL-1 $\beta$ treatment in 300,600, and $1200 \mathrm{nM}$ cortisol groups, $n=5$. WJ-MSCs, Wharton's jelly-derived mesenchymal stem cells; RTqPCR, real-time quantitative polymerase chain reaction; COL2A1, a1 chain of type II collagen; ACAN, aggrecan; MMP, matrix metalloproteinase; ADAMTS5, a disinterring and metalloproteinase with thrombospondin motifs-5. Data are the mean \pm S.E.M. ${ }^{* *} P<0.01$ vs control

transmembrane heteromeric complex of serine/threonine kinases including TGF $\beta R I$ [54]. Following the phosphorylation of the TGF $\beta$ R, Smad2, and Smad3 associate with Smad4 and then this complex migrates into the nucleus and participates in the transcriptional activation of the chondrogenic genes [55]. In the present study, after chondrogenic differentiation, the glycosaminoglycan content, as measured by Safranin-O and Alcian blue staining, and the expression levels of phenotypic genes, including COL2A1 and ACAN, as well as the expression of TGF $\beta R I$, were decreased in the IUGR group, suggesting that the low expression of TGFBRI led to the reduced responsiveness to TGF $\beta 1$ and further resulted in the poor differentiation of MSCs into chondrocytes. 


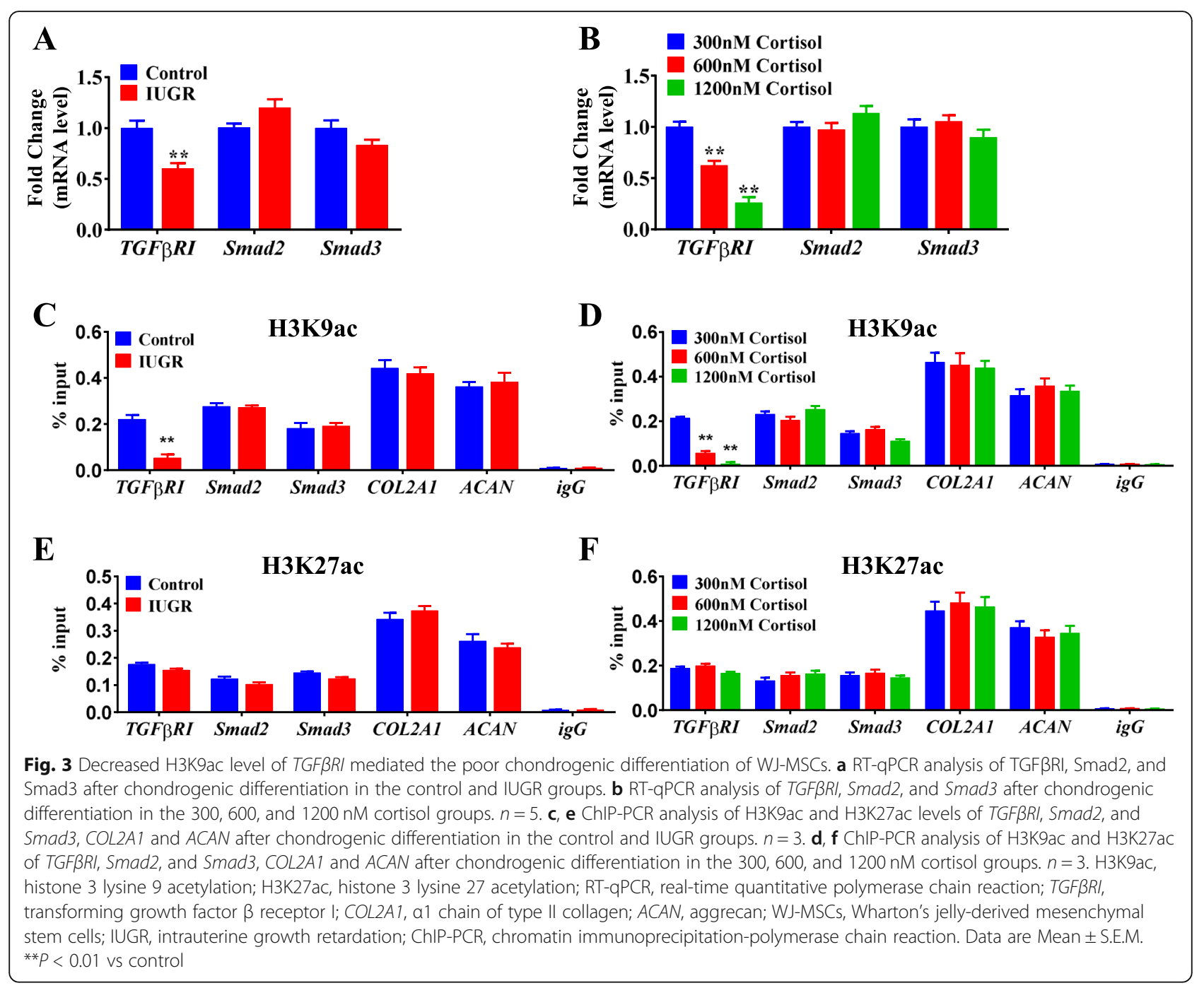

It has been reported that articular cartilage is mainly formed in embryonic and neonatal periods. After maturation, hardly any proliferation occurs in the chondrocyte. Furthermore, cartilage dysplasia is one of the risk factors of osteoarthritis $[56,57]$. Therefore, the developmental level of articular cartilage in utero influences the quality of cartilage in adulthood $[58,59]$. Based on our previous studies [14-22, 60, 61], we propose a "two-hit" theory about the fetal origination of adult osteoarthritis. More specifically, the adverse prenatal environment as the first hit induces persistent cartilage dysplasia and attenuates the resistance of cartilage to local inflammation in adulthood in the IUGR offspring. Then, an inflammatory microenvironment induced by aging, obesity-related lipid factors, and inappropriate mechanical factors [62], as the second hit, could augment the susceptibility to adult osteoarthritis. It has been revealed that IL- $1 \beta$ is the major inflammatory mediator during the osteoarthritis process [63]. In articular cartilage, the effects of TGF $\beta 1$ are counterbalanced by the action of IL- $1 \beta[64,65]$, which further indicates that the decreased activity of the TGF $\beta$ pathway might result in the reduced resistance of the cartilage in response to inflammation. In the differentiated chondrocytes from the IUGR group treated with IL-1 $\beta$, the glycosaminoglycan content and the expression of phenotypic genes were decreased more severely. Moreover, the expression of catabolic factors, including $M M P 3, M M P 13$, and ADAMTS5, was greatly enhanced. These results demonstrated that the poorly differentiated chondrocytes were more susceptible to an osteoarthritislike phenotype after IL-1 $\beta$ stimulation.

\section{Maternal glucocorticoids overexposure and the} subsequent decreased H3K9ac level of TGF $\beta R I$ played a critical role in the poor chondrogenic differentiation of WJ-MSCs from IUGR individuals

Baseline glucocorticoids level plays a crucial role in determining the maturation of fetal tissues [25]. A clinical study had reported a significant increase in cortisol level in the umbilical blood of IUGR individuals [66]. The cortisol 

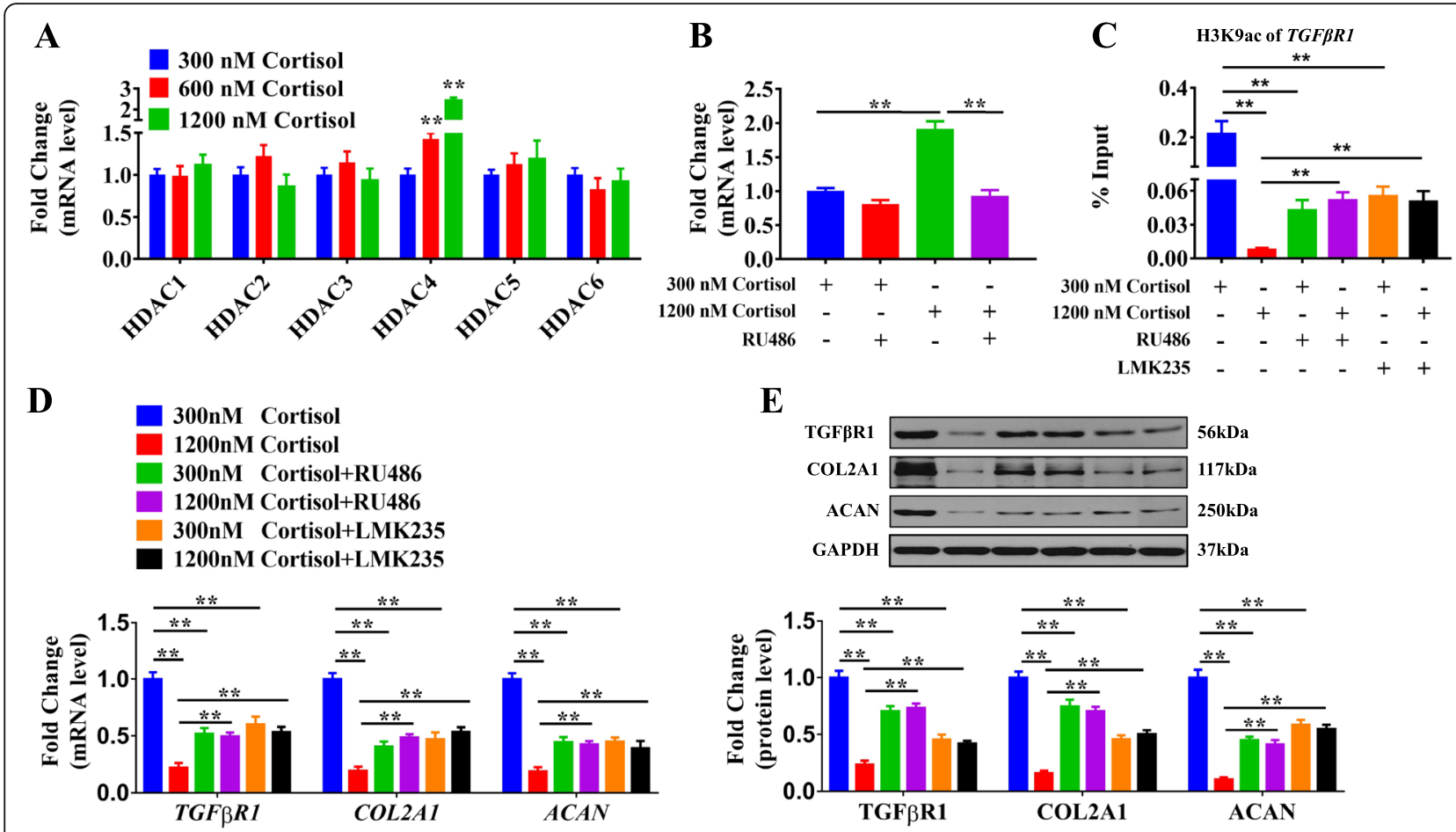

Fig. 4 GR/HDAC4 mediated the H3K9 deacetylation of TGFBRI induced by high levels of cortisol. a RT-qPCR analysis of HDACS expression in the WJ-MSCs treated with 300, 600, and $1200 \mathrm{nM}$ cortisol after chondrogenic differentiation for 7 days. $n=5$. b RT-qPCR analysis of HDAC4 expression in WJ-MSCs treated with cortisol and RU486 $(10 \mu \mathrm{M})$ after chondrogenic differentiation for 7 days. $n=5$. c ChIP-PCR analysis of the H3K9ac level of TGFBRI in WJ-MSCs treated with cortisol, and RU486 (10 $\mu \mathrm{M})$ or LMK235 (100 nM) after chondrogenic differentiation for 7 days. $n=3$. d RT-qPCR

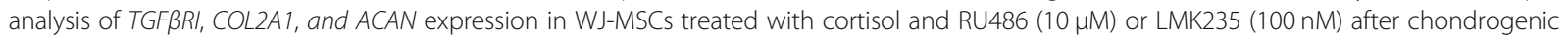
differentiation for 7 days. $n=5$. e Western blot analysis of TGF $\beta R$ I, COL2A1, and ACAN in WJ-MSCs treated with cortisol, RU486 (10 $\mu M$ ), or LMK235 $(100 \mathrm{nM})$ after chondrogenic differentiation for 7 days, $n=5$. RT-qPCR, real-time quantitative polymerase chain reaction; GR, glucocorticoid receptor; HDAC4, histone deacetylase 4; H3K9ac, histone 3 lysine 9 acetylation; TGF $\beta R I$, transforming growth factor $\beta$ receptor I; WJ-MSCs, Wharton's jelly-derived mesenchymal stem cells; ChIP-PCR, chromatin immunoprecipitation-polymerase chain reaction; igG, immunoglobulin G. Data are the mean \pm S.E.M. ${ }^{* *} P<0.01$ vs control

level (range 221 801 nM) in the umbilical blood of IUGR individuals was found significantly higher than that of the normal infants $(121 \sim 395 \mathrm{nM})$ [48]. In the present study, our results showed that the serum cortisol concentration ranged from 121 1538 nM in the IUGR individuals and from 21 369 nM in the normal individuals, which was consistent with the previous findings. Based on the above data, $300 \mathrm{nM}$ cortisol was set as the physiological concentration, while 600 and $1200 \mathrm{nM}$ were set as the pathological concentrations as the excessive maternal glucocorticoids.

An increasing number of studies have suggested that glucocorticoids are involved in intrauterine programming through epigenetic modifications, which could be inherited by the next generation [67]. Our present results further confirmed the programming effects of glucocorticoids and their potential molecular mechanism. This view was supported by our present evidence including (i) the serum cortisol level in the human IUGR umbilical blood was increased; (ii) normal human WJ-MSCs treated with excessive cortisol displayed similar features as WJ-MSCs from IUGR individuals, when undergoing the chondrogenic differentiation in vitro; (iii) The WJ-MSCs from IUGR individuals presented a poor capacity for chondrogenic differentiation and subsequent increased susceptibility to an osteoarthritis-like phenotype, due to the decreased H3K9ac and expression levels of TGF $\beta R I$ induced by excessive cortisol though GR/HDAC4. Collectively, we proposed that the excessive maternal cortisol induced decreased $\mathrm{H} 3 \mathrm{~K} 9 \mathrm{ac}$ and expression levels of TGF $\beta R I$ through GR/HDAC4 in utero, which contributed to the poor chondrogenic differentiation of WJ-MSCs from IUGR individuals and subsequently increased susceptibility to an osteoarthritis-like phenotype.

The decreased H3K9ac level of TGF $\beta R I$ could be an earlywarning biomarker for evaluating fetal cartilage development and subsequent susceptibility to osteoarthritis

It has been suggested that the changes of DNA methylation in the liver nuclear factor $4 \alpha$ gene promoter region in the blood stem cells from IUGR umbilical cord exert an essential role in the early onset of diabetes [68]. Early 


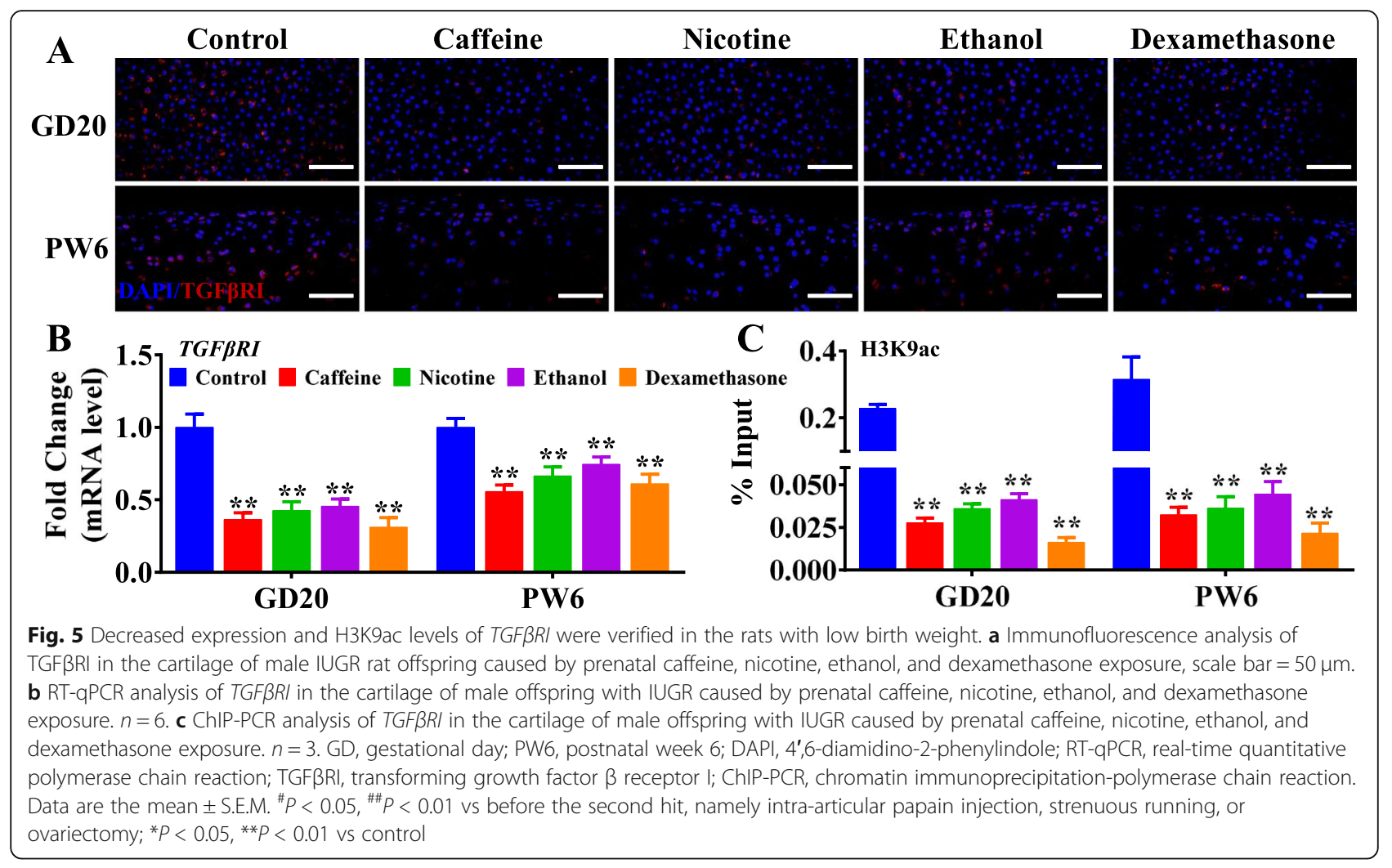

exposure to the unfavorable maternal diets resulted in an altered methylation profile, and transcriptional dysregulation of genes, which were also detectable after birth [69]. Moreover, the human umbilical cord is a tissue that can also be subjected to unfavorable factors during the prenatal period. It has been indicated that the methylation status of the retinoid X receptor alpha promoter in umbilical cord tissue might be utilized to identify individual vulnerability to the later obesity and metabolic diseases [70]. Many studies have explored the early life and childhood risk factors related to osteoarthritis and selected some markers of joint health. Cartilage defects, bone marrow lesions, and meniscal pathology (early markers of joint abnormalities) are known to occur before the clinical symptom and radiographic changes of osteoarthritis, which could be used to predict the development and progression of osteoarthritis in later life [71]. It was also reported that tibial cartilage volume could be a marker of knee joint health in young adults [72, 73]. Besides the cartilage volume, age, and mechanical stress (imbalance in the movement and physical force transmission through the joint), screening
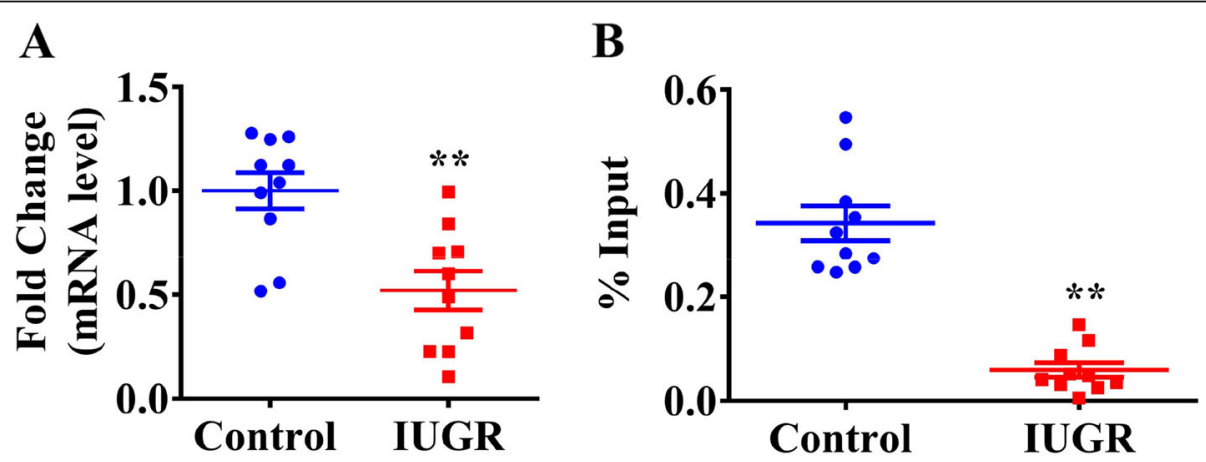

Fig. 6 Decreased expression and H3K9ac levels of TGFBRI were verified in the umbilical cord from IUGR individuals. a RT-qPCR analysis of TGF $R$ RI expression in the umbilical cord from IUGR individuals, $n=10$ in the control group, $n=10$ in the IUGR group. $\mathbf{b}$ ChIP-PCR analysis of TGF $\beta R$ I promoter in the umbilical cord from IUGR, $n=10$ in the control group, $n=10$ in the IUGR group. TGF $\beta R$, transforming growth factor $\beta$ receptor I; IUGR, intrauterine growth retardation; RT-qPCR, real-time quantitative polymerase chain reaction; ChIP-PCR, chromatin immunoprecipitationpolymerase chain reaction. Data are the mean \pm S.E.M. ${ }^{*} P<0.05,{ }^{*} P<0.01$ vs control 
epigenetic imprinting as the stable biomarkers from the existing fetal tissues like umbilical cord might be a promising strategy to predict the development of cartilage and the susceptibility to adult osteoarthritis.

For early-life events, epigenetic modification changes might act as one kind of more stable and reliable molecular markers than the expression of target genes [30]. Meanwhile, human umbilical cord is more accessible than other samples from fetuses and could also preserve the epigenetic modification change [70]. Thus, the epigenetic modification changes from the umbilical cord might be the ideal markers for early-life events. In the present study, the decreased H3K9ac level of TGFBRI induced by excess cortisol was proved to participate in the poor chondrogenic differentiation of WJ-MSCs from IUGR individuals. Meanwhile, the H3K9ac level of TGFBRI and its expression were decreased dramatically both in utero and at the postnatal stage in rat IUGR offspring, which was more susceptible to osteoarthritis in adulthood. Moreover, the H3K9ac level and mRNA expression of TGFBRI were all reduced in the umbilical cord from human IUGR newborns. Such findings suggested that the H3K9ac level of TGFBRI and its mRNA expression in the WJ-MSCs might be a predictor for cartilage dysplasia and susceptibility to osteoarthritis in the IUGR offspring. Therefore, based on these findings, we recommend the H3K9ac level of $T G F \beta R I$ in human umbilical cord as a potential biomarker for cartilage dysplasia and osteoarthritis susceptibility in the IUGR offspring, although more further evidence is needed. Except for our current study, the early-warning biomarker of fetal-originated adult osteoarthritis has never been reported by far.

\section{Conclusions}

Based on the multipotent differentiation of human WJMSCs and the "two-hit" theory in our previous studies, an innovative, two-step cell culture model was established in vitro for investigating fetal-originated adult osteoarthritis. We provided the first evidence that human WJ-MSCs from IUGR newborn exhibited poor capacity of chondrogenic differentiation and the subsequently differentiated chondrocytes presented an increased susceptibility to the osteoarthritis-like phenotype induced by IL- $1 \beta$, which was attributed to the decreased H3K9ac level and mRNA expression of TGFBRI induced by excessive cortisol through GR/HDAC4. Furthermore, we verified that the H3K9ac level of TGFBRI could be an early-warning biomarker for predicting cartilage dysplasia and susceptibility to the fetal-originated adult osteoarthritis.

\section{Supplementary Information}

The online version contains supplementary material available at https://doi. org/10.1186/s13287-021-02234-8.
Additional file 1: Fig. S1. Characterization of human Wharton's jellyderived mesenchymal stem cells (WJ-MSCS). A: The morphology of WJMSCs was photographed under a phase-contrast microscope. B-F: Flow cytometric analysis of hematopoietic markers (CD34 and CD45) and the expression of mesenchymal stem cell markers (CD73, CD90 and CD105). Fig. S2. MTS analysis of cell viability on 0 and 21 th day after chondrogenic differentiation. A: cell viability in control and IUGR groups. $n=8$. B: cell viability in 300, 600 and $1200 \mathrm{nM}$ cortisol groups. $n=8$. Data are mean \pm S.E.M. Fig. S3. Serum cortisol levels of umbilical cord blood from IUGR and normal individuals by enzyme-linked immunosorbent assay. Control group: $n=15$, IUGR group: $n=14$. IUGR, intrauterine growth retardation. Data are the mean \pm S.E.M. ${ }^{* *} P<0.01$ vs control.

\section{Abbreviations}

IUGR: Intrauterine growth retardation; WJ-MSCs: Wharton's jelly-derived mesenchymal stem cells; ELISA: Enzyme-linked immunosorbent assay;

COL2A1: a1 chain of type II collagen; ACAN: Aggrecan; TGFBRI: Transforming growth factor $\beta$ receptor I; MMP3: Matrix metalloproteinase 3; ADAMTS5: A disintegrin and metalloprotease with thromospondinmotifs; HDAC: Histone deacetylation; GAPDH: Glyceraldehyde phosphate dehydrogenase;

ChIP: Chromatin immunoprecipitation; H3K9ac: Histone 3 lysine 9 acetylation; SPF: Specific pathogen free; GD: Gestational day; PXE: Prenatal xenobiotics exposure; PW: Postnatal week

\section{Acknowledgements}

Not applicable.

\section{Authors' contributions}

H.W. contributed to the conception and the experiment design; Y.J.Q., B.L., and Y.X.W. performed the animal experiments, acquisition, analysis, and interpretation of data and wrote the manuscript. Z.H. and X.Y. performed the cell experiments, acquisition, and analysis. B.C. and Z.Z. contributed to the animal experiments and manuscript editing. J.M. and L.B.C. contributed to the study design and manuscript editing. All authors have read and approved the final submitted manuscript.

\section{Funding}

This work was supported by grants from National Key Research and Development Program of China (No. 2020YFA0803900), the National Natural Science Foundation of China (No. 81673490, 81972036, 82030111), the Major Technological Innovation Projects of Hubei Province (No. 2019ACA140, 2020BCA071), and Medical Science Advancement Program (Basic Medical Sciences) of Wuhan University (No. TFJC2018001).

\section{Availability of data and materials}

The datasets used and/or analyzed during the current study are available from the corresponding author on reasonable request.

\section{Ethics approval and consent to participate}

Human umbilical cords were harvested from patients with written consent under approval by the Ethics Committee of Zhongnan Hospital of Wuhan University (No. 2016016). Animal experiments were conducted in accordance with the protocol approved by the Experimental Center of Hubei Medical Scientific Academy (No. 2009-0004, Hubei, China).

\section{Consent for publication}

Not applicable.

\section{Competing interests}

The authors declare no competing interests.

\section{Author details}

'Department of Orthopedic Surgery, Zhongnan Hospital of Wuhan University, Wuhan 430071, China. ${ }^{2}$ Hubei Provincial Key Laboratory of Developmentally Originated Disease, Wuhan 430071, China. ${ }^{3}$ UMR 7561 CNRS-Université de Lorraine, Faculté de Médicine, Vandoeuvre-lès-Nancy, France. ${ }^{4}$ Department of Pharmacology, Wuhan University School of Basic Medical Sciences, Wuhan 430071, China. 


\section{Received: 7 September 2020 Accepted: 15 February 2021} Published online: 04 March 2021

\section{References}

1. Clynes MA, Parsons C, Edwards MH, Jameson KA, Harvey NC, Sayer AA Cooper C, Dennison EM. Further evidence of the developmental origins of osteoarthritis: results from the Hertfordshire Cohort Study. J Dev Orig Health Dis. 2014;5(6):453-8.

2. Poole J, Sayer AA, Cox V, Cooper C, Kuh D, Hardy R, Wadsworth M. Birth weight, osteoarthritis of the hand, and cardiovascular disease in men. Ann Rheum Dis. 2003;62(10):1029 author reply 1029.

3. Sayer AA, Poole J, Cox V, Kuh D, Hardy R, Wadsworth M, Cooper C. Weight from birth to 53 years: a longitudinal study of the influence on clinical hand osteoarthritis. Arthritis Rheum. 2003;48(4):1030-3.

4. Hussain SM, Ackerman IN, Wang Y, Zomer E, Cicuttini FM. Could low birth weight and preterm birth be associated with significant burden of hip osteoarthritis? A systematic review. Arthritis Res Ther. 2018;20(1):121.

5. Hussain SM, Wang Y, Wluka AE, Shaw JE, Magliano DJ, Graves S, Cicuttini FM. Association of low birth weight and preterm birth with the incidence of knee and hip arthroplasty for osteoarthritis. Arthritis Care Res (Hoboken). 2015;67(4):502-8.

6. Faraci M, Renda E, Monte S, Di Prima FA, Valenti O, De Domenico R, Giorgio E, Hyseni E. Fetal growth restriction: current perspectives. J Prenat Med. 2011;5(2):31-3.

7. Fowden $A L$, Forhead AJ. Endocrine mechanisms of intrauterine programming. Reproduction. 2004;127(5):515-26.

8. de Onis M, Blossner M, Villar J. Levels and patterns of intrauterine growth retardation in developing countries. Eur J Clin Nutr. 1998;52(Suppl 1):S5-15.

9. Wang $\mathrm{T}$, Chen M, Yan YE, Xiao FQ, Pan XL, Wang H. Growth retardation of fetal rats exposed to nicotine in utero: possible involvement of CYP1A1, CYP2E1, and P-glycoprotein. Environ Toxicol. 2009;24(1):33-42

10. Yan YE, Wang H, Feng YH. Alterations of placental cytochrome P450 1A1 and $\mathrm{P}$-glycoprotein in tobacco-induced intrauterine growth retardation in rats. Acta Pharmacol Sin. 2005;26(11):1387-94.

11. Xu D, Wu Y, Liu F, Liu YS, Shen L, Lei YY, Liu J, Ping J, Qin J, Zhang C, Chen $L B$, Magdalou J, Wang H. A hypothalamic-pituitary-adrenal axis-associated neuroendocrine metabolic programmed alteration in offspring rats of IUGR induced by prenatal caffeine ingestion. Toxicol Appl Pharmacol. 2012;264(3): 395-403.

12. Liu Y, Xu D, Feng J, Kou H, Liang G, Yu H, He X, Zhang B, Chen L, Magdalou J, Wang $\mathrm{H}$. Fetal rat metabonome alteration by prenatal caffeine ingestion probably due to the increased circulatory glucocorticoid level and altered peripheral glucose and lipid metabolic pathways. Toxicol Appl Pharmacol. 2012;262(2):205-16.

13. Liang $G$, Chen $M$, Pan $X L$, Zheng J, Wang $H$. Ethanol-induced inhibition of fetal hypothalamic-pituitary-adrenal axis due to prenatal overexposure to maternal glucocorticoid in mice. Exp Toxicol Pathol. 2011;63(7-8):607-11.

14. Tan Y, Wu Y, Ni O, Deng Y, Li J, Wang L, Shen L, Liu Y, Magdalou J, Wang H, Chen $L$. Prenatal food restriction induces poor-quality articular cartilage in female rat offspring fed a post-weaning high-fat diet and its intra-uterine programming mechanisms. Br J Nutr. 2016;116(8):1346-55.

15. Deng Y, Cao H, Cu F, Xu D, Lei Y, Tan Y, Magdalou J, Wang H, Chen L. Nicotine-induced retardation of chondrogenesis through down-regulation of IGF-1 signaling pathway to inhibit matrix synthesis of growth plate chondrocytes in fetal rats. Toxicol Appl Pharmacol. 2013;269(1):25-33.

16. Tan Y, Liu J, Deng Y, Cao H, Xu D, Cu F, Lei Y, Magdalou J, Wu M, Chen L, Wang $\mathrm{H}$. Caffeine-induced fetal rat over-exposure to maternal glucocorticoid and histone methylation of liver IGF-1 might cause skeletal growth retardation. Toxicol Lett. 2012;214(3):279-87.

17. Ni Q, Wang L, Wu Y, Shen L, Qin J, Liu Y, Magdalou J, Chen L, Wang H. Prenatal ethanol exposure induces the osteoarthritis-like phenotype in female adult offspring rats with a post-weaning high-fat diet and its intrauterine programming mechanisms of cholesterol metabolism. Toxicol Lett. 2015;238(2):117-25.

18. Luo H, Li J, Cao H, Tan Y, Magdalou J, Chen L, Wang H. Prenatal caffeine exposure induces a poor quality of articular cartilage in male adult offspring rats via cholesterol accumulation in cartilage. Sci Rep. 2015;5:17746.

19. Li J, Xiao H, Luo H, Tan Y, Ni Q, He C, Magdalou J, Chen L, Wang H. GR/ HDAC2/TGFbetaR1 pathway contributes to prenatal caffeine inducedosteoarthritis susceptibility in male adult offspring rats. Food Chem Toxicol. 2020;140:111279.
20. Tie K, Tan Y, Deng Y, Li J, Ni Q, Magdalou J, Chen L, Wang H. Prenatal nicotine exposure induces poor articular cartilage quality in female adult offspring fed a high-fat diet and the intrauterine programming mechanisms. Reprod Toxicol. 2016:60:11-20.

21. Ni Q, Tan Y, Zhang X, Luo H, Deng Y, Magdalou J, Chen L, Wang H. Prenatal ethanol exposure increases osteoarthritis susceptibility in female rat offspring by programming a low-functioning IGF-1 signaling pathway. Sci Rep. 2015;5:14711.

22. Xiao H, Xie X, Wen Y, Tan Y, Shangguan Y, Li B, Magdalou J, Wang H, Chen L. Subchondral bone dysplasia partly participates in prenatal dexamethasone induced-osteoarthritis susceptibility in female offspring rats. Bone. 2020;133:115245.

23. Aigner T, Richter W. OA in 2011: age-related OA--a concept emerging from infancy? Nat Rev Rheumatol. 2012;8(2):70-2.

24. Vina ER, Kwoh CK. Epidemiology of osteoarthritis: literature update. Curr Opin Rheumatol. 2018;30(2):160-7.

25. Fowden AL, Li J, Forhead AJ. Glucocorticoids and the preparation for life after birth: are there long-term consequences of the life insurance? Proc Nutr Soc. 1998:57(1):113-22.

26. Reynolds RM. Glucocorticoid excess and the developmental origins of disease: two decades of testing the hypothesis--2012 Curt Richter Award Winner. Psychoneuroendocrinology. 2013;38(1):1-11.

27. Kajantie E. Early-life events. Effects on aging. Hormones (Athens). 2008;7(2): 101-13.

28. Moisiadis VG, Matthews SG. Glucocorticoids and fetal programming part 1: outcomes. Nat Rev Endocrinol. 2014;10(7):391-402.

29. Moisiadis VG, Matthews SG. Glucocorticoids and fetal programming part 2: mechanisms. Nat Rev Endocrinol. 2014;10(7):403-11.

30. Boekelheide K, Blumberg B, Chapin RE, Cote I, Graziano JH, Janesick A, Lane R, Lillycrop K, Myatt L, States JC, Thayer KA, Waalkes MP, Rogers JM. Predicting later-life outcomes of early-life exposures. Environ Health Perspect. 2012:120(10):1353-61.

31. Xu D, Zhang B, Liang G, Ping J, Kou H, Li X, Xiong J, Hu D, Chen L, Magdalou J, Wang H. Caffeine-induced activated glucocorticoid metabolism in the hippocampus causes hypothalamic-pituitary-adrenal axis inhibition in fetal rats. PLoS One. 2012;7(9):e44497.

32. Chen M, Wang T, Liao ZX, Pan XL, Feng YH, Wang H. Nicotine-induced prenatal overexposure to maternal glucocorticoid and intrauterine growth retardation in rat. Exp Toxicol Pathol. 2007:59(3-4):245-51.

33. Tanthaisong $P$, Imsoonthornruksa S, Ngernsoungnern A, Ngernsoungnern $P$ Ketudat-Cairns M, Parnpai R. Enhanced chondrogenic differentiation of human umbilical cord Wharton's jelly derived mesenchymal stem cells by GSK-3 inhibitors. PLoS One. 2017;12(1):e0168059.

34. Batsali AK, Kastrinaki MC, Papadaki HA, Pontikoglou C. Mesenchymal stem cells derived from Wharton's jelly of the umbilical cord: biological properties and emerging clinical applications. Curr Stem Cell Res Ther. 2013:8(2):144-55.

35. Broholm C, Olsson AH, Perfilyev A, Hansen NS, Schrolkamp M, Strasko KS, Scheele C, Ribel-Madsen R, Mortensen B, Jorgensen SW, Ling C, Vaag A. Epigenetic programming of adipose-derived stem cells in low birthweight individuals. Diabetologia. 2016;59(12):2664-73.

36. Delahaye F, Wijetunga NA, Heo HJ, Tozour JN, Zhao YM, Greally JM, Einstein $\mathrm{FH}$. Sexual dimorphism in epigenomic responses of stem cells to extreme fetal growth. Nat Commun. 2014;5:5187.

37. Sukarieh $R$, Joseph R, Leow SC, Li Y, Loffler M, Aris IM, Tan JH, Teh AL, Chen L, Holbrook JD, Ng KL, Lee YS, Chong YS, Summers SA, Gluckman PD, Stunkel W. Molecular pathways reflecting poor intrauterine growth are found in Wharton's jelly-derived mesenchymal stem cells. Hum Reprod. 2014;29(10):2287-301.

38. Sharples AP, Stewart CE, Seaborne RA. Does skeletal muscle have an 'epi'memory? The role of epigenetics in nutritional programming, metabolic disease, aging and exercise. Aging Cell. 2016;15(4):603-16.

39. Tan PY, Chang CW, Duan K, Poidinger M, Ng KL, Chong YS, Gluckman PD, Stunkel W. E2F1 orchestrates transcriptomics and oxidative metabolism in Wharton's jelly-derived mesenchymal stem cells from growth-restricted infants. PLoS One. 2016;11(9):e0163035.

40. Ahn J, Park EM, Kim BJ, Kim JS, Choi B, Lee SH, Han I. Transplantation of human Wharton's jelly-derived mesenchymal stem cells highly expressing TGFbeta receptors in a rabbit model of disc degeneration. Stem Cell Res Ther. 2015;6:190

41. De Ceuninck F, Lesur C, Pastoureau P, Caliez A, Sabatini M. Culture of chondrocytes in alginate beads. Methods Mol Med. 2004;100:15-22. 
42. Deng Y, Li TQ, Yan YE, Magdalou J, Wang H, Chen LB. Effect of nicotine on chondrogenic differentiation of rat bone marrow mesenchymal stem cells in alginate bead culture. Biomed Mater Eng. 2012;22(1-3):81-7.

43. Billings $P C$, Yang E, Mundy C, Pacifici M. Domains with highest heparan sulfate-binding affinity reside at opposite ends in BMP2/4 versus BMP5/6/7: implications for function. J Biol Chem. 2018;293(37):14371-83.

44. Gutiérrez ML, Guevara J, Barrera LA. Semi-automatic grading system in histologic and immunohistochemistry analysis to evaluate in vitro chondrogenesis. Univ Sc. 2012;17(2):167-78.

45. Tolcos M, Petratos S, Hirst JJ, Wong F, Spencer SJ, Azhan A, Emery B, Walker DW. Blocked, delayed, or obstructed: what causes poor white matter development in intrauterine growth restricted infants? Prog Neurobiol. 2017;154:62-77.

46. Park KW, Lee KM, Yoon DS, Park KH, Choi WJ, Lee JW, Kim SH. Inhibition of microRNA-449a prevents IL-1 beta-induced cartilage destruction via SIRT1. Osteoarthr Cartil. 2016;24(12):2153-61.

47. Grandjean P, Barouki R, Bellinger DC, Casteleyn L, Chadwick LH, Cordier S, Etzel RA, Gray KA, Ha EH, Junien C, Karagas M, Kawamoto T, Paige Lawrence B, Perera FP, Prins GS, Puga A, Rosenfeld CS, Sherr DH, Sly PD, Suk W, Sun Q, Toppari J, van den Hazel P, Walker CL, Heindel JJ. Life-long implications of developmental exposure to environmental stressors: new perspectives. Endocrinology. 2015;156(10):3408-15.

48. Mericq V, Medina P, Kakarieka E, Marquez L, Johnson M C, and Iniguez G, Differences in expression and activity of 11 beta-hydroxysteroid dehydrogenase type 1 and 2 in human placentas of term pregnancies according to birth weight and gender. Eur J Endocrinol, 2009. 161(3): p. 419-425.

49. Kang SW, Do HJ, Han IB, Shin DA, Kim HO, Kim JH, Lee SH. Increase of chondrogenic potentials in adipose-derived stromal cells by co-delivery of type I and type I| TGFbeta receptors encoding bicistronic vector system. J Control Release. 2012;160(3):577-82.

50. Matsunobu $T$, Torigoe $K$, Ishikawa $M$, de Vega S, Kulkarni AB, Iwamoto Y, Yamada Y. Critical roles of the TGF-beta type I receptor ALK5 in perichondrial formation and function, cartilage integrity, and osteoblast differentiation during growth plate development. Dev Biol. 2009;332(2): 325-38.

51. Crudo A, Suderman M, Moisiadis VG, Petropoulos S, Kostaki A, Hallett M, Szyf M, Matthews SG. Glucocorticoid programming of the fetal male hippocampal epigenome. Endocrinology. 2013;154(3):1168-80.

52. Kadmiel M, Cidlowski JA. Glucocorticoid receptor signaling in health and disease. Trends Pharmacol Sci. 2013;34(9):518-30

53. Hartmann K, Koenen M, Schauer S, Wittig-Blaich S, Ahmad M, Baschant U, Tuckermann JP. Molecular actions of glucocorticoids in cartilage and bone during health, disease, and steroid therapy. Physiol Rev. 2016;96(2):409-47.

54. Bauge C, Legendre F, Leclercq S, Elissalde JM, Pujol JP, Galera P, Boumediene K. Interleukin-1 beta impairment of transforming growth factor beta1 signaling by down-regulation of transforming growth factor beta receptor type II and up-regulation of Smad7 in human articular chondrocytes. Arthritis Rheum. 2007;56(9):3020-32.

55. Wang W, Rigueur D, and Lyons K M, TGFbeta signaling in cartilage development and maintenance. Birth Defects Res C Embryo Today, 2014. 102(1): p. 37-51.

56. Pitsillides AA, Beier F. Cartilage biology in osteoarthritis--lessons from developmental biology. Nat Rev Rheumatol. 2011;7(11):654-63.

57. Kornak U, Mundlos S. Genetic disorders of the skeleton: a developmental approach. Am J Hum Genet. 2003;73(3):447-74.

58. Dreier R. Hypertrophic differentiation of chondrocytes in osteoarthritis: the developmental aspect of degenerative joint disorders. Arthritis Res Ther. 2010;12(5):216.

59. Hayes DW Jr, Brower RL, John KJ. Articular cartilage. Anatomy, injury, and repair. Clin Podiatr Med Surg. 2001;18(1):35-53

60. Li J, Luo H, Wu Y, He Z, Zhang L, Guo Y, Ma L, Magdalou J, Chen L, Wang H. Gender-specific increase in susceptibility to metabolic syndrome of offspring rats after prenatal caffeine exposure with post-weaning high-fat diet. Toxicol Appl Pharmacol. 2015;284(3):345-53.

61. Tie K, Zhang X, Tan Y, Deng Y, Li J, Ni Q, Wang H, Chen L. Intrauterine lowfunctional programming of IGF1 by prenatal nicotine exposure mediates the susceptibility to osteoarthritis in female adult rat offspring. FASEB J. 2016;30(2):785-97.
62. Mobasheri A, Rayman MP, Gualillo O, Sellam J, van der Kraan P, Fearon U. The role of metabolism in the pathogenesis of osteoarthritis. Nat Rev Rheumatol. 2017;13(5):302-11.

63. Malemud CJ, Islam N, Haqqi TM. Pathophysiological mechanisms in osteoarthritis lead to novel therapeutic strategies. Cells Tissues Organs. 2003;174(1-2):34-48

64. Redini F, Mauviel A, Pronost S, Loyau G, Pujol J. Transforming growth factor beta exerts opposite effects from interleukin-1 beta on cultured rabbit articular chondrocytes through reduction of interleukin-1 receptor expression. Arthritis Rheum. 1993;36(1):44-50.

65. Lum ZP, Hakala BE, Mort JS, Recklies AD. Modulation of the catabolic effects of interleukin-1 beta on human articular chondrocytes by transforming growth factor-beta. J Cell Physiol. 1996;166(2):351-9.

66. Goland RS, Jozak S, Warren WB, Conwell IM, Stark RI, Tropper PJ. Elevated levels of umbilical cord plasma corticotropin-releasing hormone in growthretarded fetuses. J Clin Endocrinol Metab. 1993;77(5):1174-9.

67. O'Donnell KJ, Meaney MJ. Fetal origins of mental health: the developmental origins of health and disease hypothesis. Am J Psychiatry. 2017;174(4):319-28.

68. Einstein F, Thompson RF, Bhagat TD, Fazzari MJ, Verma A, Barzilai N, Greally $J M$. Cytosine methylation dysregulation in neonates following intrauterine growth restriction. PLoS One. 2010;5(1):e8887.

69. Heo HJ, Tozour JN, Delahaye F, Zhao Y, Cui L, Barzilai N, Einstein FH. Advanced aging phenotype is revealed by epigenetic modifications in rat liver after in utero malnutrition. Aging Cell. 2016;15(5):964-72.

70. Godfrey KM, Sheppard A, Gluckman PD, Lillycrop KA, Burdge GC, McLean C, Rodford J, Slater-Jefferies JL, Garratt E, Crozier SR, Emerald BS, Gale CR, Inskip HM, Cooper C, Hanson MA. Epigenetic gene promoter methylation at birth is associated with child's later adiposity. Diabetes. 2011;60(5):1528-34.

71. Pelletier JP, Cooper C, Peterfy C, Reginster JY, Brandi ML, Bruyere O, Chapurlat R, Cicuttini F, Conaghan PG, Doherty M, Genant H, Giacovelli G, Hochberg MC, Hunter DJ, Kanis JA, Kloppenburg M, Laredo JD, McAlindon T, Nevitt M, Raynauld JP, Rizzoli R, Zilkens C, Roemer FW, Martel-Pelletier J, Guermazi A. What is the predictive value of MRI for the occurrence of knee replacement surgery in knee osteoarthritis? Ann Rheum Dis. 2013;72(10): 1594-604.

72. Burgkart R, Glaser C, Hinterwimmer S, Hudelmaier M, Englmeier KH, Reiser $M$, Eckstein F. Feasibility of $T$ and $Z$ scores from magnetic resonance imaging data for quantification of cartilage loss in osteoarthritis. Arthritis Rheum. 2003:48(10):2829-35.

73. Cohen ZA, Mow VC, Henry JH, Levine WN, Ateshian GA. Templates of the cartilage layers of the patellofemoral joint and their use in the assessment of osteoarthritic cartilage damage. Osteoarthr Cartil. 2003;11(8):569-79.

\section{Publisher's Note}

Springer Nature remains neutral with regard to jurisdictional claims in published maps and institutional affiliations.
Ready to submit your research? Choose BMC and benefit from:

- fast, convenient online submission

- thorough peer review by experienced researchers in your field

- rapid publication on acceptance

- support for research data, including large and complex data types

- gold Open Access which fosters wider collaboration and increased citations

- maximum visibility for your research: over $100 \mathrm{M}$ website views per year

At $\mathrm{BMC}$, research is always in progress.

Learn more biomedcentral.com/submission 